\title{
The effect of drive on attention
}

J. G. FORD, M. D. MORRIS, AND F. J. BREMNER, DEPARTMENT OF PSYCHOLOGY, TRINITY UNIVERSITY, San Antonio, Tex. 78212

This study demonstrated that differences in drive level resulting from hours of deprivation are measurable by means of power spectral analysis of EEG data.

This study was designed to investigate the extent to which traditional drive variables effect EEG patterns independent of traditional learning variables. It was reasoned that when a nonnoxious light stimulus was regularly presented for several consecutive hours to rats which had been food deprived for different lengths of time that the resulting data would bear on the above question. Therefore, spectral analysis of EEG data recorded from hippocampal electrodes was performed during habituation of Ss to a light stimulus, after various periods of food deprivation.

Subjects. Six adult male Holtzman rats ranging in weight from $250-400 \mathrm{~g}$ were bilaterally implanted with bipolar stainless steel electrodes in both hippocampi. The electrode sites were as follows: Hippocampus (Bregma; posterior $3 \mathrm{~mm}$, lateral $3 \mathrm{~mm}$, and $3 \mathrm{~mm}$ below the skull).

The six Ss were divided into three groups of two Ss each. One group, GLLD (Experiment G, Low, Low, Drive), was maintained on an ad lib food condition during the experiment. Group GLD (Experiment G, Low Drive) was deprived of food (Wayne rat feed) $3 \mathrm{~h}$ prior to placement in the apparatus. The third group, GHD (Experiment G, High Drive), was deprived of food $22.5 \mathrm{~h}$ prior to entering the experimental paradigm.

Apparatus. A Beckman Model T oscillograph and an Ampex sp $300 \mathrm{FM}$ analog tape recorder were used to record the neuro-electric responses. The analog tapes were then spectrally analyzed by an IBM 1800 computer. The presentation of the stimulus events was controlled by a Digital Equipment Corporation Logic Programmer. The programmer also numerically coded each trial.

Procedure. Each $\mathrm{S}$ was placed on a $4 \times 8$ in. platform atop a 36 in. high tower inside a $4 \times 4 \times 8 \mathrm{ft}$ electrically shielded sound attenuating chamber. One week postsurgery, all Ss underwent the treatment which was similar to that used by Bremner \& Ford (in press). In this paradigm each $S$ was habituated to a light stimulus. The stimulus to be habituated was the offset of an indirect light. The light level from this source, measured at the platform was $0.5 \mathrm{ft}-\mathrm{c}$. Ambient light level with the light off at the platform was 4.0 ft-c. The stimulus was programmed to extinguish every $3 \mathrm{sec}$ and remain off for $1.36 \mathrm{sec}$. Each $\mathrm{S}$ remained in the chamber for six consecutive hours. Electroencephalographic data was sampled at the following time period: $0 \mathrm{~h}$, $.25 \mathrm{~h}, .5 \mathrm{~h}, 1 \mathrm{~h}, 2 \mathrm{~h}, 3 \mathrm{~h}, 4 \mathrm{~h}, 5 \mathrm{~h}$, and $6 \mathrm{~h}$.

Results. Ten consecutive stimulus presentations were chosen from the EEG samples taken at each time period.- These analog EEG records were then converted to discrete values by an A-D converter and an IBM 1800 computer. One second epochs (beginning at the stimulus onset) of these converted data were spectrally analyzed (Walters, 1963). Ten spectra from each time period were then summed and averaged yielding an average spectra for each time period.

An analysis of variance was then performed on these spectra. The frequency variable was found significant $(F=80.06, \mathrm{df}=3)$ as was the Frequency by Treatment effect $(F=4.46$, df $=6)$. The data analyzed were the percentage power values at frequencies 4 ,

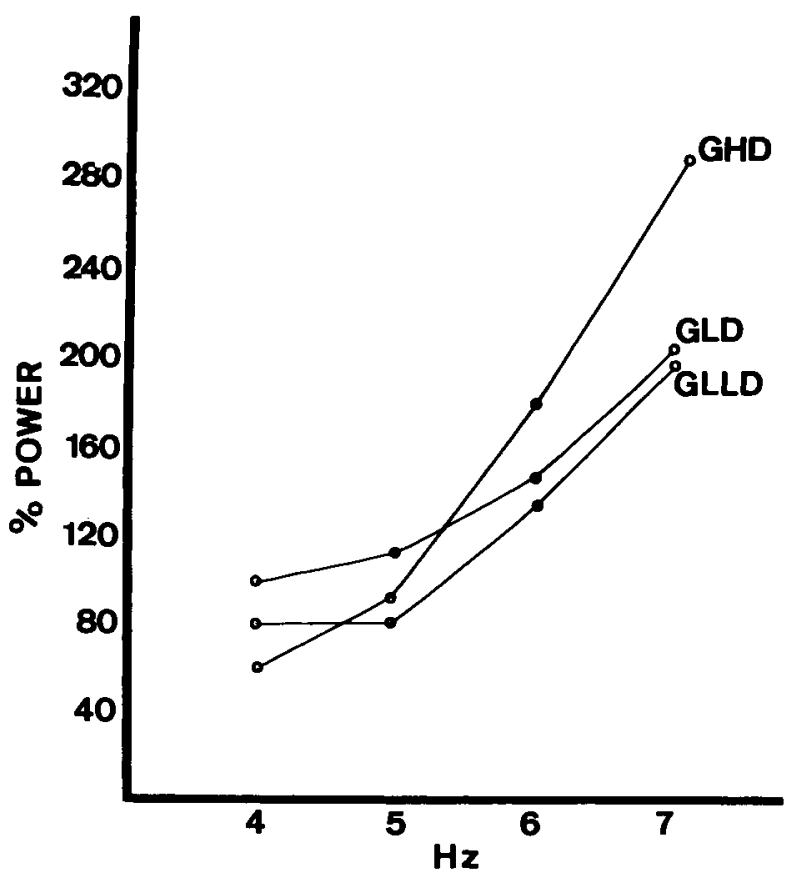

Fig. 1. Plot showing significant difference in frequency distributions of EEG data as a result of manipulating antecedent drive conditions ( $T$ by $F$ ). The $G$ represents Experiment $G$ while HD stands for high drive, LD for low drive, and LLD for very low drive.

$5,6,7 \mathrm{~Hz}$. The significant $\mathrm{F}$ by $\mathrm{T}$ interaction is diagramed in Fig. 1. Special notice should be given to the group GHD. While the power is low in frequencies 4 and $5 \mathrm{~Hz}$, the power in frequencies 6 and $7 \mathrm{~Hz}$ is above the GLLD and GLD respective powers at the same frequencies.

Discussion. The results reported above indicate that EEG data is manipulable by changes in hours of food deprivation. Since hippocampal EEG in the frequency ranges reported here has been taken as a correlate of attention (Green \& Arduini, 1954; Bremner, in press), it is interesting to speculate on the relationship between traditional drive manipulation and electrophysiological correlates of attention. A logical interpretation of these results is that drive stands in a multiplicative relationship with attention in much the same way that it does with learning.

\section{REFERENCES}

BREMNER, F. J. Hippocampal correlates of classical conditioning. J. comp. physiol. Psychol., in press.

BREMNER, F. J. \& FORD, J. G. Habituation of neuro-electric responses negative results. Neuropsychologia, in press.

GREEN, J. D. \& ARDUINI, A. A. Hippocampal electrical activity in arousal. J. of Neurophysiol., 1954, 17, 533-557.

WALTER, D. O. Spectral analysis for electroencephalograms: mathematical determination of neurophysiological relationships from records of limited duration. Exp. Neurol., 1963, 8, 155-181. 